\title{
The Role of Reactive Form -Focused Oral Feedback in the Devalopment of Iranian EFL Learners'Grammatical Accuracy in Writing Skill
}

\author{
Flora Efaf Soltani \\ Hooshang Azari
}

Department of English language, Tonekabon Branch

Islamic Azad University, IRAN.

Floraefaf@yahoo.com

Doi: 10.5901/mjss.2013.v4n4p157

\section{Abstract}

\begin{abstract}
There are 2 kinds of feedback in the form focused instruction that can help SLA students to extend their linguistic resources. This article investigates the role of Reactive Form Focused instruction that involves corrective feedback and other attempts to draw learners' attention to Language-Form during interaction and practicing correcting writing errors. In this study 60 students who had enrolled in "advanced writing" course in Azad University of Rasht, IRAN, selected and passed OPT, 20 of subject's distributed in to two groups. After Pre- test the errors in their written data were analyzed by the researcher and two other raters in terms of identifying and classifying of the grammatical errors which were found in tenses, articles, ....This classification was used as guidelines for negotiation in experimental class. In experimental class, from the recorded class activities, Reactive Form Focused Episodes/RFFES extracted in order to grantee whether the negotiation happened around the pre-test grammar errors/classification. comparison between the means of pre and post test showed that Reactive Form Focused Oral Feedback/Negotiation has more effects in correcting grammatical errors than Red pen Underlined error correction in advanced writing class of Azad University of Rasht.
\end{abstract}

Key Terms: EFL learners; Feedback; Reactive Form- Focuced Episode/ RFFE; Negotiation;

\section{Introduction}

There is a growing body of evidence regarding the positive role of corrective feedback in L2 learning. However, there is not yet a universal agreement among SLA researchers that corrective feedback has any direct impact on L2 writing grammatical accuracy (Pashazadeh 2009). Since Truscott published his 1996 article, "The case against grammar correction in L2 writing classes," debate about whether and how to give L2 students feedback on their written grammatical errors has been of considerable interest.

Research in support of reactive form focused instruction suggest that at the moment when students have something to say that a focus on language can be most effective ,rather than postponing a focus on language until a subsequent language lesson. Simply correcting and negotiating about the errors in class help, they explicitly think about their errors. In this study a kind of oral feedback followed in Iranian EFL writing classrooms for the purpose of correcting the learners' written output.

\section{Background and literature review}

Meanwhile the role of negotiation and its effects on the development of interlanguage have recently received considerable theoretical attention in the field SLA (Lyster and Ranta 1997; Van den Branden 1997; McDonough and Mackey 2000; Oliver and Mackey 2003; Nassaji and Fotos 2004). However, most of the research in this area has focused on oral errors. The role of feedback on writing involves complex issues and needs to be considered within the total context in which the feedback is given. (Hamdollah Ravand, 2010).

With the study of interlanguage, errors came to be interpreted as dialectal and not erroneous. In this continuum moving from the L1 to the target language, a student's evolving interlanguage seemed to follow a built -in syllabus that, in the absence of fossilization, would lead to something resembling the L2 without intervention (Corder 1978). In the seventies, Burt and Kiparsky (1974) distinguished global errors from local errors. Global errors were those that showed up frequently in student production whereas local errors were one time occurrences. With more communicative views of 
language acquisition, errors were recognized as listener defined (Edmondson, 1993). Only those elements that caused confusion on the part of the listener warranted correction. The treatment of errors or the teacher response to errors is more commonly referred to as feedback.

Feedback is the general heading for various techniques that are currently used in many EFL courses to respond to student writing. Feedback is defined as any procedure used to inform a learner whether an instructional response is right or wrong (Lalande, 1982). Overall, three broad meanings of feedback have been examined (Kulhavy and Wager, 1993). First, in a motivational meaning, some feedback, such as praise, could be considered a motivator that increases a general behavior (e.g., writing or revision activities overall).Second, in a reinforcement meaning, feedback may specifically reward or criticize very particular prior behaviors (e.g., a spelling error or particular approach to a concluding paragraph). This piece of the definition came from the Law of Effect (Thorndike, 1927). Third, in an informational meaning, feedback might consist of information used by a learner to change performance in a particular direction (rather than just towards or away from a prior behavior). This piece of the definition came from information-processing theories (Pressey, 1926, 1927). In the context of writing, the informational processing has the most importance.

\subsection{The interactional model affecting feedback application to second language writing}

According to Hamdollah Ravand (2010), one of the most common approaches for investigating the role of feedback in second language writing has been to examine the head of that feedback - that is, whether the feedback is provided by teacher or by another student. Also Feedback preferences indicate that ESL students greatly value teacher written feedback and consistently rate it more highly than alternative forms such as peer feedback. (Leki, 1991; Saito, 1994). Particularly those from cultures where teachers are highly directive, generally expect teachers to notice and comment on their errors and may feel resentful if their teacher do not do so. Despite students 'positive attitudes toward teachers' feedback its contribution to students' writing development is not still clear. Ferris et al (1997), for instance, found that although three quarters of substantive teachers' comments on drafts were used by students, only half of their revisions in response to these could be considered as improvements and a third actually made matters worse.

Peer feedback has become a widespread practice in both L1 and L2 composition classrooms. Some of the benefits claimed for this method include fostering a sense of audience, developing students' critical reading and analysis skills, receiving scaffold support, as well as gaining a deeper understanding of the communicative nature of the writing process (Allaei and Connor, 1990; Porto, 2001) -all within a learner- centered environment that increases student motivation and independence (Chaudron, 1984) and does not penalize the students for errors (Diaz, 1991). When solving their writing problems by using peer revision, students receive immediate feedback, instead of days or weeks later.

Some researchers have invoked Vygotsky's theories on social interaction and scaffold help (Ferris ,et all, 1997). According to Vygotsky (1978), knowledge is social in nature; thus, the process of interacting with a more knowledgeable person allows the learner to internalize both linguistic and cognitive abilities, including writing skills. Finally, it has been noted that in oral feedback sessions, nonverbal communication, such as differences in intonation and facial expressions, can serve to mitigate criticism and thus encourage a more collaborative stance between the speaker and the writer.

\subsection{Total Debates}

Feedback is defined as any procedure used to inform a learner whether an instructional response is right or wrong (Lalande, 1982).

An increasing number of studies have been investigating whether certain types of corrective feedback are more likely than others to help L2 students improve the accuracy of their writing. In reviewing some of these studies, Truscott (1996) reported that none of them (Kepner, 1991; Semke, 1984) found significant differences across any of the different treatment groups (content comments only; error correction only; a combination of content comments and error correction; error identification, but no correction) but when the evidence from studies that have considered other feedback distinctions is examined, it is clear that such a conclusion should at this stage be treated with caution.

Only a few studies have attempted to directly investigate whether $\mathrm{L} 2$ students who receive written corrective orall feedback on their errors are able to improve the accuracy of their writing compared with those who do not receive error feedback orally. Each of these studies (Kepner, 1991) reported that there was no significant difference in the writing accuracy of the students. However, it needs to be noted that (Sheppard, 1992) did not include a non-feedback control group. Although as cited in Bitchener (2008) Fathman and Whalley (1990) found that fewer grammatical errors were made by students who received error feedback, this particular study examined text revisions and not new pieces of writing over time. Thus, there is clearly a need for research that not only compares the effects of receiving corrective 
feedback and no corrective feedback but also examines the long-term effects of such treatments (Ferris 2004; Truscott, 1999).

A good number of studies have distinguished between direct and indirect feedback strategies and investigated the extent to which they facilitate greater accuracy (Lalande, 1982). Direct or explicit feedback occurs when the teacher identifies an error and provides the correct form, while indirect strategies refer to situations when the teacher indicates that an error has been made but does not provide a correction, thereby leaving the student to diagnose and correct it. Additionally, studies examining the effect of indirect feedback strategies have tended to make a further distinction between those that do or do not use a code. Coded feedback points to the exact location of an error, and the type of error involved is indicated with a code (for example, PS means an error in the use or form of the past simple tense). Uncoded feedback refers to instances when the teacher underlines an error, circles an error, or places an error tally in the margin, but, in each case, leaves the student to diagnose and correct the error.

Contrary to surveys which reveal that both students and teachers have a preference for direct, explicit feedback rather than indirect feedback (Ferris and Roberts, 2001), several studies report that the latter leads to either greater or similar levels of accuracy over time (Frantzen, 1995; Lalande, 1982).However, neither the Lalande nor the Robb et al. studies had control groups which received no correction and neither study found statistically significant differences between the treatment conditions.

According to Bitchener (2008), in one study (Ferris et al., 2001) has investigated the effects of different treatment conditions on both text revisions and new pieces of writing. Discussing the findings of the study, Ferris (2004) reported that direct error correction led to more correct revisions (88\%) than indirect error feedback (77\%). Over the course of the semester, however, it was noted that students who received indirect feedback reduced their error frequency ratios substantially more than those who received direct feedback.

Compared with this growing but far from conclusive body of research on the written feedback strategies of teachers, virtually few researches have investigated the effect of other feedback strategies, such as oral feedback. Many writing teachers consider teacher-student negotiation to be potentially more effective than written corrective feedback because they provide an opportunity for clarification, instruction, and interaction (Bitchener, Young and Cameron, 2005), but published empirical research on this option are few which means that this popularly held belief cannot be taken as evidence of effectiveness.

Since the interactive feedback that takes place in a classroom context, the interaction is not always dyadic and the response to the error is not always from the same student who had made the error. Therefore, successful correction of the error does not necessarily indicate that the same student who had made the error succeed in correcting the error.

More commonly, researchers have made the argument for oral feedback by advocating the use of one to one teacher student conferences. Such researchers have asserted that conferences are more effective than traditional written methods because, in conferences, the teacher -reader is a live audience, and thus is able to ask for clarification, check the comprehensibility of oral comments made, help the writer sort through problems, and assist the student in decision making (Keh, 1990). Other researchers have invoked Vygotsky's theories on social interaction and scaffold help (e.g., Ferris, 1997; villamiland Guerrero, 1996). According to Vygotsky (1978), knowledge is social in nature; thus, the process of interacting with a more knowledgeable other (e.g., the teacher) allows the learner to internalize both linguistic and cognitive abilities, including writing skills (Hedgcock and Lefkowitz, 1994; Lockhart, 1996) .

\subsection{Categorization of Grammatical Errors in writing class}

Within the field of applied linguistics, most of the studies of foreign language learning have adopted one of the following as a basis of accounting for or explaining errors: the Contrastive Analysis Hypothesis (CA), Error Analysis (EA) and the Interlanguage (IL) approach (Fisiak,1981). The procedures for EA are stated as follows:
a) A corpus of language is defined.
b) The errors in the corpus are identified.
c) The errors are classified.
d) The errors are explained.
e) The errors are evaluated (Ellis, 1985:51-52)

\section{Statement of the problem}

Unfortunately, in ESL classes correcting errors for students will probably not help them learn to correct errors by themselves. Correcting and negotiating about the errors in class help students explicitly think about their errors but, What 
kinds of feedbacks/negotiations are most helpful in writing class for eliminating students writing errors? Does reactive form-focused oral feedback through negotiation have a direct effect on Iranian EFL learners' grammatical errors in writing classes? Are students more likely to benefit from feedback that involves negotiation than feedback without negotiation in writing classes? Does the success of the feedback provided in writing classes on students grammatical errors depend on the amount of negotiation given (limited and extended)?

A kind of oral corrective feedback happens in Iranian EFL writing classrooms for the purpose of correcting the learners' written output. This study examined the form focused oral feedback in the context of addressing written errors. Writing is the investigative base of this study but grammar accuracy is its focal point.

\section{Materials and Methods}

In order the Role of Reactive Form-Focused Oral Feedback through negotiation in the Development of Iranian EFL Learners' Grammatical Accuracy in Writing Skill to be tested, 60 students who were English major in their second level, passed OPT , 20 were selected as sample (mean +-1), distributed 2 groups ,Experimentyal group and control group ,they were subjects, who learnt English as L2 at Azad University of Rasht ,IRAN. They were enrolled in "advanced writing" course. After Pre test the written data were analyzed by the researcher and two other raters in terms of identifying and classifying of the grammatical errors which were found in tenses, prepositions, articles, active and passive voice, verbs and morphological errors.this categorization was used as guidelines in experemental class,by instructure, in order to control the correction of students errors.

During a summer term, each session, written productions of 2 group of learners, were analyzed and classified by researcher and 3or 4 papers that were most close to our pre test grammatical categorization extracted to be discussed in class with students .So 2 major works were done in Experimental class, recognizing written grammatical errors and Reactive form focused oral feedback about the errors were performed and emphasized in Experimental class .The interactions between teachers and EFL students in correcting students grammatical errors in their writing work, audiorecorded, transcribed by the name of RFFEs / Reactive Form Focused Episodes, and compared in terms of the frequency of types of negotiation as Extended and limited, with this method thr Researcher granted the oral feedback Inegotiation happening in the class ferequently and secured whether the negotiation happened according to (from highest to the lowest percentage of students written errors) the grammar classification.

The Experimental class's student actively negotiating their grammatical errors or their peer classmate grammatical errors, But in control group class's student only receiving their corrected papers with minimal written corrected form of errors(red pen correcting) .One thing was observable in this two class the students in experimental class were much more motivated to see their grammatical errors than control group after receiving their corrected papers.

Originally Data was collected through tests and classroom observation. At the beginning of the term,the researcher used the proficiency test, Oxford Placement test (OPT), as one of her instruments which were used to assure the homogeneity of the two groups in terms of their language proficiency.Recorders were other subsidiary instruments for recording the interaction of all participants of the study with the teacher. Other main instruments were Pre Test, a Final Student- Specification Error Identification/Correction test as Post Test and T-Test.

The source of instruction in both classes was the book: Advanced writing- Author- Florsita Bustamanteh Publisher; SAMT.

In 10 seassion 8 chapter covered.According to the data recorded in 10 DVD RFFEs happened almost $60 \%$ on those errors that was categorized according to pre test.The last session post test was performed in both classes .

\section{Results and Discussions}

By use of Inferential and discriptive statistics, the result showes that the effect of reactive form-focused oral feed back on EFL learners' grammatical accuracy was more than usual writing class.

Discriptively the comparision of the pre-test and post-test of the control group showes less differences than comparision of the post-test and pre-test of the experimental class. 
Table 1. Pre-Test ,Descriptive Statistics, Control Group and Experimental Group

\begin{tabular}{|c|c|c|c|c|c|c|}
\hline & & $\mathrm{N}$ & Minimum & Maximum & Mean & Std. Deviation \\
\hline$\overline{\text { Sum1 }}$ & & 10 & 6.5 & 18.5 & 13.250 & 3.6152 \\
\hline Sum2 & & 10 & 8.0 & 16.5 & 13.000 & 2.9627 \\
\hline $\begin{array}{l}\text { Valid } \\
\text { wise) }\end{array}$ & $\mathrm{N}$ & (list10 & & & & \\
\hline
\end{tabular}

* Sum1, The sum of score of 2 Raters, Control group

*Sum2, The sum of scores of 2 Raters, Experimental group

Table 2. Post-Test, Descriptive Statistics, Control and Experimental Groups

\begin{tabular}{llllll}
\hline & N & Minimum & Maximum & Mean & Std. Deviation \\
\hline${ }^{*}$ Sum1 & 10 & 11.5 & 20.0 & 15.100 & 2.7769 \\
${ }^{*}$ Sum2 & 10 & 12.5 & 20.0 & 17.200 & 3.0750 \\
Valid & N10 & & & & \\
(listwise) & & & & & \\
\hline
\end{tabular}

* Sum1, The sum of score of 2 Raters, Control group

*Sum2, The sum of scores of 2 Raters, Experimental group

Based on The Role of Reactive Form-Focused Oral Feedback in the Development of EFL Learners' Grammatical Accuracy in Writing Skill as well as t-value, It is obvious that the observed value of $t 4.047$ exceeds the critical value and thus by $95 \%$ confidence it can be indicated that the post test means of the two groups of the study are significantly different.

Table 3. Paired Samples Test

\begin{tabular}{|c|c|c|c|c|c|c|c|c|c|}
\hline & & \multicolumn{5}{|c|}{ Paired Differences } & \multirow[b]{3}{*}{$\mathrm{t}$} & \multirow[b]{3}{*}{ df } & \multirow[b]{3}{*}{ Sig.(2-tailed) } \\
\hline & & \multirow[b]{2}{*}{ Mean } & \multirow[b]{2}{*}{ Std. Deviation } & \multirow{2}{*}{$\begin{array}{l}\text { Std. Error } \\
\text { Mean }\end{array}$} & \multicolumn{2}{|c|}{$\begin{array}{c}95 \% \text { Confidence Interval of } \\
\text { the Difference }\end{array}$} & & & \\
\hline & & & & & Lower & Upper & & & \\
\hline Pair 1 & $\begin{array}{l}\text { E.Post.Sum - } \\
\text { C.Post.Sum }\end{array}$ & 2.2000 & 1.7192 & .5437 & .9702 & 3.4298 & 4.047 & 9 & .003 \\
\hline
\end{tabular}

Post Test the result of comparing pre and post test showed that Reactive Form Focused Oral Feedback/Negotiation has more positive effects in correcting grammatical errors than Red pen Underlined error correction in writing class of Azad University of Rasht.It is noticible ,The success of the feedback provided depended on the amount of negotiation given (extended). This part needs more investigation.

\section{Conclusion}

This descriptive study tries to investigate the roll of interaction in the reactive form focused oral feedback in writing class, and correcting Iranian EFL learners' written errors. Its findings may encourage language teachers' more use of negotiation in delivering feedback.Objective measure of Reactive form-focused episodes through negotiation needs more practical study in different levels of writing class

\section{References}

A.Pashazadeh,Hamideh Marefat(2010).The longterm Effect of selective written grammar feedback on EFL learner's acquisition of articles.Pazhuhesh-e Zabanha-ye Khareji,No.56,Special Issue,English, PP.49-67

Allaei, S. K., and Connor, U. (1990). Using performative assessment instruments with ESL student writers. In L. Hamp-Lyons (Ed.), Assessing second language writing in academic contexts (pp. 227-240). 
Bitchener, J., Young, S., and Cameron, D. (2005). The effect of different types of corrective feedback on ESL student writing. Journal of Second Language Writing, 14, 191-205.

Bitchener, J. (2008). Evidence in support of written corrective feedback. Journal of Second Language Writing, 17, 102-118.

Chaudron, C. (1984). The effects of feedback on students' composition revisions. RELC Journal, 15, 1-14.

Corder, S.P., (1978). Language-learner language.

Diaz, D. (1991). Writing, collaborative learning, and community. College ESL, 1(1), $19-24$.

Edmondson, W. (1993). What Do Learners Get out of Teachers' Treatment of Errors? Paper read at the $10^{\text {th }}$ AlLA Congress, Amsterdam

Ferris, D. R., Pezone, S., Tade, C. R., and Tinti, S. (1997). Teacher commentary on student writing: Descriptions and implications. Journal of Second Language Writing, 6.

Ferris, D. R. (1999). The case for grammar correction in L2 writing classes. A response to Truscott (1996). Journal of Second Language Writing, 8, 1-10.

Ferris, D. R. (2004). The "Grammar Correction" debate in L2 writing: Where are we, and where do we go from here? (and what do we do in the meantime. . .?). Journal of Second Language Writing, 13, 49-62.

Ferris, D. R., and Roberts, B. (2001). Error feedback in L2 writing classes: How explicit does it need to be? Journal of Second Language Writing, 10, 161-184.

Frantzen, D. (1995). The effects of grammar supplementation on written accuracy in an intermediate Spanish content course. Modern Language Journal, 79, 329-344.

Fisiak,(1981).Contrastive Lingustics and the Language Teacher.

Hamdollah Ravand,Abbas Esmlami Rasekh .(2010) Feedback in ESL Writing:Toward an Interactional Approach , Journal of Language Teaching and Research,vol.2,No.5 pp.1136-1145.

Hedgcock, J., and Lefkowitz, N. (1994). Feedback on feedback: Assessing learner receptivity to teacher response in L2 composing. Journal of Second Language Writing, 3(2), 141-163.

Kepner, C. G. (1991). An experiment in the relationship of types of written feedback to the development of second language writing skills. Modern Language Journal, 75, $305,313$.

Kulhavy, R. W., and Wager, W. (1993). Feedback in programmed instruction: Historical context and implications for practice.

Lalande, J. F. (1982). Reducing composition errors: An experiment. Modern Language Journal, 66, 140-149.

Leki, 1. (1991). The preferences of ESL students for error correction in college- level writing classes. Foreign Language Annals, 24, 203218.

Lockhart, C. (1996). Analyzing talk in ESL peer response groups: Stances, functions, and content. Language Learning, 45(4), 605-655.

Lyster, R., and Ranta, L. (1997). Corrective feedback and learner uptake: Negotiation of form in communicative classrooms. Studies in Second Language Acquisition, 19, 37-66.

Lyster, R., and Mori, H. (2006). Interactional feedback and instructional counterbalance. Studies in Second Language Acquisition, 28, 269-300

McDonough, K. and A. Mackey. (200). Communicative tasks, conversational interaction and linguistic forms: an empirical study of Thai. Foreign Language Annuals 33/1: 82 - 92.

Nassaji, H. and S. Fotos. (2004). Current developments in the teaching of grammar. Annual Review of Applied Linguistics 24: $126-45$.

Oliver, R. and A. Mackey. (2003). Interactional context and feedback in child ESL classrooms. The Modern Language Journal 87/4: $519-533$.

Pressey, S. L. (1926). A simple device which gives tests and scores-and teaches. School and Society, 23,373-376. [67]

Pressey, S. L. (1927). A machine for automatic teaching of drill material. School and Society, 25, 549-552

Saito, H. (1994). Teachers' practices and students' preferences for feedback on second language writers: A case study of adult ESL learners. TESL Canada Journal, 11(2), 46-70.

Spade, N. (1997). "Form-focused instruction and second language acquisition: a review of classroom and laboratory research". Language Teaching 30/2, 75-37.

Semke, H. (1984). The effects of the red pen. Foreign Language Annals, 17, 195- 202

Sheppard, K. (1992). Two feedback types: Do they make a difference? RELC Journal, 23, 103-110.

Truscott, J. (1996). The case against grammar correction in L2 writing classes. Language Learning, 46, 327-369.

Truscott, J. (1999). The case for " the case for grammar correction in L2 writing classes": A response to Ferris. Journal of Second Language Writing, 8, 111-122.

Van den Brande, K. (1997). Effects of negotiation on language learners' output. Language Learning 47/ 4: 589-636.

Villamil, O. S., and Guerrero, M. C. M. de (1996). Peer revision in the L2 classroom: Social-cognitive activities, mediating strategies and aspects of social behavior. Journal of Second Language Writing, 5(1), 51-75. 